\title{
miRNA-24 Gene Sequence, DHFR -829C-T Genotypes, and Methotrexate Response in Mexican Patients with Rheumatoid Arthritis
}

\author{
Martha Rocio Hernández-Preciado, ${ }^{1}$ María Cristina Morán-Moguel, ${ }^{2}$ Ingrid Patricia Dávalos-Rodríguez, ${ }^{3,4}$ \\ Christian Michel Enríquez-Barajas, ${ }^{5}$ Juan Paulo Valdovinos-Maravilla, ${ }^{5}$ Ana Lilia Díaz-Pérez, \\ Daniel Efraín Silva-Castro, ${ }^{5}$ Laura González-López,,6 Jorge Ivan Gámez-Nava, 1,7 \\ Mario Alberto Aceves-Aceves, ${ }^{8}$ and Mario Salazar-Páramo ${ }^{1,8}$
}

Aim: The present study looked for variation in the miRNA-24 sequence, and evaluated the associations between the dihydrofolate reductase $(D H F R)$ gene-829 C-T polymorphism and plasma DHFR concentrations with response to methotrexate (MTX) treatment in Mexican patients with rheumatoid arthritis (RA).

Methods: A total of 135 women with RA were classified as responders (disease activity score [DAS28] <3.2) or nonresponders to MTX (DAS28 > 3.2). We determined the genotype of the patients using the polymerase chain reaction-restriction fragment length polymorphism method. Plasma DHFR enzyme levels and mi-RNA24 sequences were assessed by enzyme-linked immunosorbent assay (ELISA) and Sanger sequencing, respectively. Allelic frequencies and the genotypic distribution of the polymorphism were analyzed by the chi-square test. Results: The genotype frequencies of the DHFR -829C-T polymorphism among responders were $37.0 \% \mathrm{CC}$, $52.1 \% \mathrm{CT}$, and $10.9 \% \mathrm{TT}$ and for nonresponders were $33.9 \% \mathrm{CC}, 56.4 \% \mathrm{CT}$, and $9.7 \% \mathrm{TT}$. No significant differences in genotype frequencies were found between the groups $(p=0.88)$. The DHFR levels relative to genotype for responders were $6.8 \pm 2.7,6.1 \pm 2.7$, and $6.5 \pm 1.5 \mathrm{ng} / \mathrm{mL}$ for CC, CT, and TT, respectively, and for nonresponders were $6.5 \pm 2.0,6.1 \pm 3.1$, and $7.4 \pm 1.8 \mathrm{ng} / \mathrm{mL}$ for CC, CT, and TT, respectively. No significant differences were found between the two groups. Similarly, both groups showed no sequence variations in miRNA-24 gene.

Conclusion: The $-829 \mathrm{C}-\mathrm{T}$ polymorphism of DHFR gene was not associated with response to MTX by RA patients, and no variations were found in the miRNA-24 sequence that might modify the response to treatment or DHFR enzyme levels in a Mexican population with RA.

Keywords: rheumatoid arthritis, methotrexate, miRNA-24, DHFR genotype

\footnotetext{
${ }^{1}$ Doctorado en Farmacología, Departamento de Fisiología, Centro Universitario de Ciencias de la Salud, Universidad de Guadalajara, Guadalajara, Jalisco, México.

${ }^{2}$ Departamento de DFMI, Centro Universitario de Ciencias de la Salud, Universidad de Guadalajara, Guadalajara, Jalisco, México.

${ }^{3}$ División de Genética, Centro de Investigación Biomédica de Occidente, Instituto Mexicano del Seguro Social, Guadalajara, Jalisco México.

${ }^{4}$ Departamento de Biología Molecular y Genómica, DGH, Centro Universitario de Ciencias de la Salud, Universidad de Guadalajara, Guadalajara, Jalisco, México.

${ }^{5}$ Servicio Social en Investigación. Comisión Interinstitucional para la Formación de Recursos Humanos para la Salud, Secretaría de Salud, México.

${ }^{6}$ Hospital General Regional No. 110, Instituto Mexicano del Seguro Social, Guadalajara, Jalisco, México.

${ }^{7}$ Unidad de Investigación Biomédica 02, Unidad Médica de Alta Especialidad, Hospital de Especialidades, Centro Médico Nacional de Occidente, Instituto Mexicano del Seguro Social. Guadalajara, Jalisco, México.

${ }^{8}$ División de Investigación en Salud, Unidad Médica de Alta Especialidad, Hospital de Especialidades, Centro Médico Nacional de Occidente, Instituto Mexicano del Seguro Social, Guadalajara, Jalisco, México.

(C) Martha Rocio Hernández-Preciado et al. 2019; Published by Mary Ann Liebert, Inc. This Open Access article is distributed under the terms of the Creative Commons Attribution Noncommercial License (http://creativecommons.org/licenses/by-nc/4.0/) which permits any noncommercial use, distribution, and reproduction in any medium, provided the original author(s) and the source are cited.
} 


\section{Introduction}

$\mathbf{R}$ HEUMATOID ARTHRITIS (RA) is a systemic autoimmune disease (Churov et al., 2015). Methotrexate (MTX) is a disease-modifying antirheumatic drug (DMARD) and the most commonly used first-line agent for the treatment of RA (Aslibekyan et al., 2014). The pharmacological action of MTX is the inhibition of the enzyme dihydrofolate reductase (DHFR), which interferes with DNA replication and cell proliferation (Jekic et al., 2016; Sramek et al., 2017). Several factors influence the response to MTX, including genetic factors (Berkani et al., 2017) such as micro-RNAs (miRNAs). miRNAs are small noncoding single chain RNAs that are $\sim 22$ nucleotides in length and can regulate the expression of genes by degrading messenger RNA (mRNA) or repressing mRNA translation (Akhtar et al., 2016). The miRNA-24 regulates the development of adult hematopoietic progenitor cells (Roy et al., 2015). miRNA-24 requires base complementarity to bind to $D H F R$ to regulate its expression.

A single nucleotide polymorphism (SNP) in the miRNA gene or the $3^{\prime}$ untranslated region ( $3^{\prime}$-UTR) of the target gene could create, destroy, or modify the miRNA binding site and influence resistance or sensitivity to treatment or expression of a target gene by interfering with miRNA function (Passetti et al., 2009; Song et al., 2014). The DHFR -829C-T polymorphism is located in the $3^{\prime}$-UTR of the gene on chromosome $5 q 14$. The miRNA-24 sequences lie 14 bp downstream of this region (Murata et al., 2013). In the absence of miRNA-24 binding to the DHFR gene, DHFR is overexpressed and MTX resistance can occur (Mishra et al., 2007).

A change in the sequence of the gene coding for miRNA24 could counteract the effects of the wild or polymorphic variant of the DHFR gene and may be linked to MTX response by RA patients. The aim of this study was to evaluate the DHFR -829C-T polymorphism, plasma DHFR concentrations, the miRNA-24 gene sequence, and the association with the response to MTX treatment in Mexican RA patients.

\section{Materials and Methods}

\section{Study subjects}

This case-control study included 135 patients treated at an outpatient clinic between August 2015 and December 2016. Inclusion criteria were women, Mexican, $\geq 18$ years old, RA diagnosed according to the American College of Rheumatology (Arnett et al., 1988), and oral MTX treatment (5$20 \mathrm{mg}$ per week) for at least 1 year before initiation of the study. We excluded patients who were being treated with leflunomide or biological DMARDs, as well as patients who had incomplete clinical data and women who stopped MTX treatment.

The patients were classified into two groups, responders and nonresponders, based on their response to MTX according to the disease activity score (DAS28) (Dhaon et al., 2017). The responder group comprised 73 patients having a DAS28 score $\leq 3.2$, and the nonresponder group had 62 patients who had a DAS28 score $>3.2$.

\section{Clinical and laboratory evaluations}

All patients were evaluated according to sociodemographic and clinical characteristics, and blood samples were collected from all 135 study participants. The plasma samples were subsequently used for quantification of DHFR enzyme levels using the human dihydrofolate reductase enzyme-linked immunosorbent assay (ELISA) Kit (MyBioSource, Inc., San Diego, CA). The erythrocyte sedimentation rate (ESR) of the samples was determined by the Westergren method and levels of C-reactive protein (CRP) and anticitrullinated protein antibodies (ACPAs) were determined by nephelometry and ELISA, respectively. Genomic DNA was extracted from the remaining sample using the modified Miller technique (Miller et al., 1988).

\section{DHFR -829C-T genotyping}

The $-829 \mathrm{C}-\mathrm{T}$ polymorphism was detected by polymerase chain reaction-restriction fragment length polymorphism (PCR-RFLP) using the following primers: forward, $5^{\prime}$-CTTCT CCAAGACCCCAACTG-3' and reverse, 5'-CTTCCAGGTT GTTTTCAATTTTT-3' (Gómez-Gómez et al., 2012). The PCR amplification product (269 bp) was digested with $5 \mathrm{U}$ of the TspRI enzyme (New England Biolabs, Beverly, MA). The digested products were analyzed on $8 \%$ polyacrylamide gels (29:1) stained with silver nitrate. We obtained 203, 45, and $21 \mathrm{bp}$ fragments for the CC genotype, 248, 203, 45, and $21 \mathrm{bp}$ fragments for the CT genotype, and 248 and $21 \mathrm{bp}$ fragments for the TT genotype.

\section{Identification of miRNA-24 gene sequence}

Amplification of the miRNA-24 gene was performed by endpoint PCR. The following primers were designed and used to amplify a $519 \mathrm{bp}$ fragment from chromosome 9 that contains the miRNA-24 gene: forward, 5'-CGCGGTGAA CTCTCTCTTGT-3' and reverse, 5'-CACGCACCCACTC TAACTGT-3'. Sanger sequencing was performed using an ABI 3730XL instrument (Applied Biosystems, Foster City, CA). The miRNA-24 gene sequence was analyzed using the Sequencher 5.4.6 program (Gene Codes Corporation, Ann Arbor, MI).

\section{Statistical analysis}

Quantitative variables are presented as means and standard deviations. The qualitative variables are expressed as frequencies and percentages. The analysis was based on nonparametric statistics. The allelic frequencies and genotypic distribution of the polymorphisms were compared between the study groups by the chi-squared and Mann-Whitney $U$ tests. Statistical analyses were carried out using the SPSS statistical package, v. 21 (Chicago, IL). $p<0.05$ was considered significant.

\section{Ethics}

This study was approved by the Research Committee of the participating center (R-2015-1301-68). All study participants voluntarily provided written informed consent.

\section{Results \\ Clinical and laboratory characteristics}

The sociodemographic characteristics were determined for the responders and nonresponders (Table 1). The mean MTX dose received by the responders and nonresponders was 
Table 1. Characteristics of Responders and Nonresponders to Methotrexate Treatment

\begin{tabular}{|c|c|c|c|}
\hline & $\begin{array}{c}\text { Responders } \\
\mathrm{n}=73\end{array}$ & $\begin{array}{c}\text { Nonresponders } \\
\mathrm{n}=62\end{array}$ & p-Value \\
\hline \multicolumn{4}{|l|}{ Demographics } \\
\hline Age (years), mean $\pm \mathrm{SD}$ & $57 \pm 12$ & $55 \pm 10$ & 0.93 \\
\hline Smoker, $n(\%)$ & $4(5.5)$ & $7(11.3)$ & 0.36 \\
\hline Family history, $n(\%)$ & $37(50.7)$ & $30(48.4)$ & 0.93 \\
\hline \multicolumn{4}{|l|}{ Disease characteristics } \\
\hline $\operatorname{ESR}(\mathrm{mm} / \mathrm{h})$, mean $\pm \mathrm{SD}$ & $23.2 \pm 10$ & $27.8 \pm 13$ & 0.56 \\
\hline $\mathrm{CRP}(\mathrm{mg} / \mathrm{mL})$, mean $\pm \mathrm{SD}$ & $7.1 \pm 7.2$ & $13.2 \pm 14$ & 0.014 \\
\hline ACPAs, no. of positive/no. of total (\%) & $40 / 58(69.0)$ & $30 / 54(55.6)$ & 0.20 \\
\hline \multicolumn{4}{|l|}{ Treatment } \\
\hline \multirow[t]{2}{*}{ MTX dosage $(\mathrm{mg})$, mean \pm SD } & $11.8 \pm 4.9$ & $11.4 \pm 3.6$ & \multirow{2}{*}{0.29} \\
\hline & $\mathrm{n}(\%)$ & $\mathrm{n}(\%)$ & \\
\hline NSAIDs & $64(87.7)$ & $55(88.7)$ & 1.00 \\
\hline Sulfasalazine & $39(53.4)$ & $30(48.4)$ & 0.68 \\
\hline Corticosteroids & $31(42.5)$ & $43(69.4)$ & 0.003 \\
\hline Chloroquine & $17(23.3)$ & $17(27.4)$ & 0.72 \\
\hline Genotypic distribution & $\mathrm{n}(\%)$ & $\mathrm{n}(\%)$ & \\
\hline $\mathrm{CC}$ & $27(37.0)$ & $21(33.9)$ & \multirow{6}{*}{0.88} \\
\hline CT & $38(52.1)$ & $35(56.4)$ & \\
\hline TT & $8(10.9)$ & $6(9.7)$ & \\
\hline Allelic frequency & $\mathrm{n}(\%)$ & $\mathrm{n}(\%)$ & \\
\hline $\mathrm{C}$ & $92 \overline{(63.0)}$ & $77(62.1)$ & \\
\hline $\mathrm{T}$ & $54(37.0)$ & $47(37.9)$ & \\
\hline
\end{tabular}

Bold values indicate $p<0.05$.

CC: homozygous genotype; CT: heterozygous genotype; TT: homozygous variant genotype.

ACPAs, anticitrullinated protein antibodies; CRP, C-reactive protein; ESR, erythrocyte sedimentation rate (Westergren method); MTX, methotrexate; NSAIDs, nonsteroidal anti-inflammatory drugs; SD, standard deviation.

similar at $11.8 \pm 4.9$ and $11.4 \pm 3.6 \mathrm{mg}$ per week, respectively. ESR values also showed no statistically significant difference between the two groups. Meanwhile, CRP values were nearly twofold higher for nonresponders than responders $(13.2 \pm 14$ vs. $7.1 \pm 7.2 \mathrm{mg} / \mathrm{mL})$ and this difference was statistically significant $(p=0.014)$. The rate of corticosteroid use was also significantly higher for nonresponders than responders (69.4\% vs. $42.5 \% ; p=0.003)$.

\section{DHFR -829C-T genotypes}

No differences were found in the distribution of genotypes between the responders and nonresponders (Table 1). The predominant genotype in both groups was $\mathrm{CT}$, and the most frequent allele in both groups was $\mathrm{C}$.

Table 2. Plasma Levels of the DHFR Enzyme ACCORDING TO DHFR -829C-T GENOTYPE

\begin{tabular}{|c|c|c|c|}
\hline Genotype & $\begin{array}{c}\text { Responders } \\
\text { Mean } \pm S D(\mathrm{n}=50)\end{array}$ & $\begin{array}{c}\text { Nonresponders } \\
\text { Mean } \pm S D(\mathrm{n}=38)\end{array}$ & $\begin{array}{c}\mathrm{p}- \\
\text { Value }\end{array}$ \\
\hline $\mathrm{CC}$ & $6.8 \pm 2.7(21)$ & $6.5 \pm 2.0$ & 0.31 \\
\hline CT & $6.1 \pm 2.6(24)$ & $6.1 \pm 3.1(25)$ & 0.94 \\
\hline $\mathrm{TT}$ & $6.5 \pm 1.5(5)$ & $7.4 \pm 1.8(2)$ & 0.72 \\
\hline
\end{tabular}

The values are expressed in $\mathrm{ng} / \mathrm{mL}$.

$\mathrm{CC}$ : homozygous genotype; CT: heterozygous genotype; TT: homozygous variant genotype.

DHFR, dihydrofolate reductase.

\section{Quantification of the DHFR enzyme-genotype-DAS28}

Based on the genotype and DAS28 classification, the DHFR enzyme concentration was analyzed for $88(65 \%)$ of the study subjects (Table 2). The highest mean DHFR concentration was found for responders carrying the $\mathrm{CC}$ genotype $(6.8 \mathrm{ng} / \mathrm{mL})$ and in nonresponders carrying the TT genotype $(7.4 \mathrm{ng} / \mathrm{mL})$. No significant differences were found when the groups were compared.

\section{Sequencing of miRNA-24}

We analyzed the sequence of the 68 bases corresponding to the mature sequence of miRNA-24. Among the 130 samples analyzed, no genetic mutation was found in either chain of the miRNA-24 sequence in the responder or nonresponder group (Fig. 1).

\section{Discussion}

The relationship between MTX response and the DHFR -829C-T polymorphism, plasma DHFR concentration, and variants in the miRNA-24 gene sequence has not been investigated in previous studies. In a 135 patient cohort of Mexican patients with RA, we found no association between these parameters and MTX treatment response. The sociodemographic characteristics were similar among responders and nonresponders to MTX treatment. However, the DAS28 score based on CRP levels was significantly higher in the nonresponders group, as was the rate of corticosteroid use 


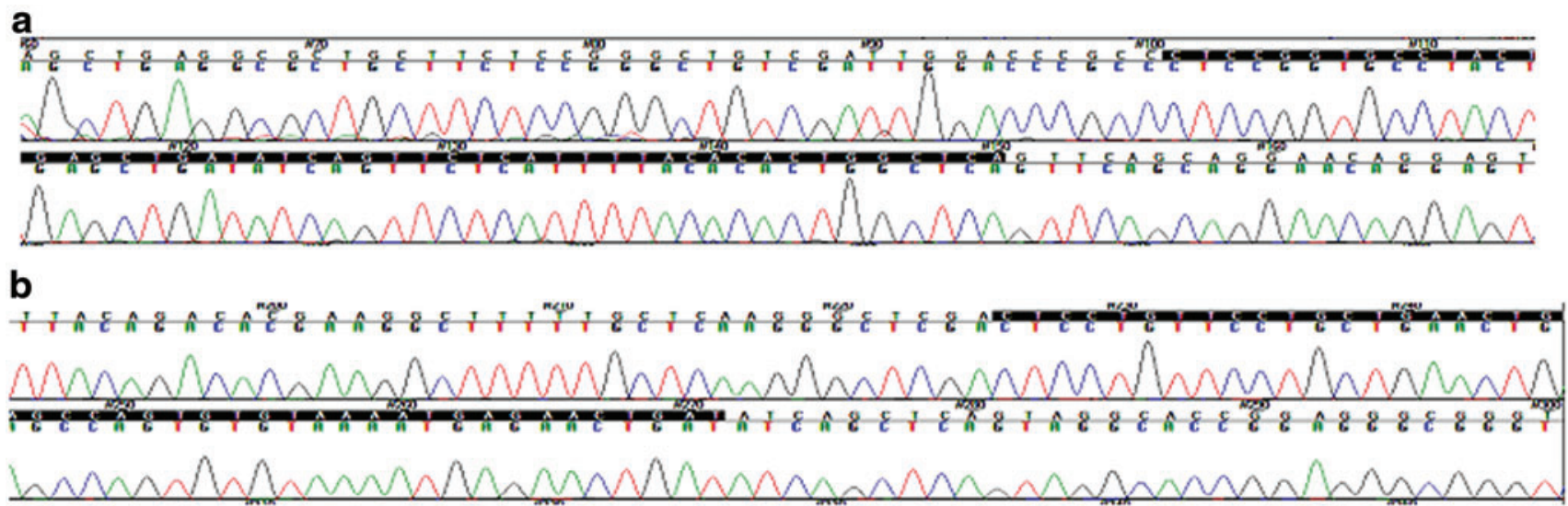

FIG. 1. Electropherograms of the $m i R N A-24$ gene sequence. (a) $5^{\prime}-3^{\prime}$ chain. (b) $3^{\prime}-5^{\prime}$ chain. Color images are available online.

$(p=0.003)$. This finding could be associated with a need of nonresponders for additional medication to reduce pain and inflammation due to the high level of RA activity.

\section{Genotypes}

The only published study on the DHFR -829CT polymorphism in a Mexican population was carried out by Gómez-Gómez et al. (2012), who analyzed the response to MTX by children with acute lymphoblastic leukemia. In that study, the authors determined that the Mexican population was in Hardy-Weinberg equilibrium and identified a positive relationship between the $\mathrm{T}$ allele and risk of disease relapse due to a lack of response to MTX. They also found that the predominant genotype among responders and nonresponders was CT (63.6\% and $81.3 \%$, respectively), which is consistent with the findings for this study. In contrast, Goto et al. (2001) reported that for a Japanese population the CC genotype was the most frequent $D H F R-829 \mathrm{C}-\mathrm{T}$ genotype. Other studies associated the presence of the T allele with MTX treatment failure (Mishra et al., 2007). However, our analysis of minor homozygous genotypes showed no significant difference between responders and nonresponders $(10.9 \%$ responders vs. $9.7 \%$ for nonresponders).

As this study is an exploratory work and no previous information has been described similar to the aim of this research in Mexican patients, we considered the small sample size a limitation with a probably insufficient statistical power to detect small differences between the comparison of allele and genotype frequencies observed in responders and nonresponders to MTX treatment (Table 1). However, the sample size allows us to perform this comparison. In addition, we observe that despite an increase in the number of patients, the allelic frequencies are maintained (a minimum of 100 alleles are required).

\section{Level of DHFR enzyme}

Some studies suggested that elevated DHFR levels are related to failure to respond to MTX treatment (O'Dell et al., 2013; Jekic et al., 2016). We quantified the DHFR enzyme levels in 88 patients and found no significant difference between the groups. Although DHFR enzyme levels have been analyzed in cancer cell cultures (Mishra et al., 2007), to our knowledge our study is the first to analyze the association of DHFR enzyme concentrations in RA patients with DHFR $-829 \mathrm{C}-\mathrm{T}$ genotypes. All of our patients had levels more than $6.1 \pm 3.1 \mathrm{ng} / \mathrm{mL}$, which suggests that patients with RA have DHFR enzyme overexpression relative to that seen in healthy populations (Naithani et al., 2016). Galbiatti et al. (2013) found that DHFR gene expression levels in cancer cells dosedependently increased with MTX treatment. This could in part explain why we saw similar elevations in DHFR enzyme levels in both groups, because patients in this study had begun MTX treatment at least 1 year before study initiation.

\section{$\operatorname{miRNA-24}$}

Alterations in the miRNA gene region may play an important role in RA pathogenesis or treatment response and may alter miRNA expression and/or maturation (Li et al., 2014). Gutierrez-Camino et al. (2018) determined that the TT genotype of SNP rs2648841 in the premature sequence of the miR-1208 gene has a protective function in leukemia patients being treated with MTX. Our study is the first to analyze the miRNA-24 gene sequence with respect to RA and showed that there were no differences in the gene sequence between MTX responders and nonresponders.

\section{Conclusion}

The DHFR -829C-T polymorphism is not associated with MTX response by RA patients, and no variations were found in the miRNA-24 gene that could modify the response to MTX treatment or DHFR enzyme levels. Thus, additional studies to examine other polymorphisms in the DHFR pathway are needed to explain the differences in response to MTX treatment by RA patients.

\section{Acknowledgments}

This research was supported by the Instituto Mexicano del Seguro Social (IMSS; Grant number FIS/IMSS/PROT/G15/ 1430). M. Hernández-Preciado received a scholarship from CONACYT (589885). 


\section{Author Disclosure Statement}

No competing financial interests exist.

\section{References}

Akhtar MM, Micolucci L, Islam MS, et al. (2016) Bioinformatic tools for microRNA dissection. Nucleic Acids Res 44: 24-44.

Arnett FC, Edworthy SM, Bloch DA, et al. (1988) The American Rheumatism Association 1987 revised criteria for the classification of rheumatoid arthritis. Arthritis Rheum 31: 315-324.

Aslibekyan S, Brown EE, Reynolds RJ, et al. (2014) Genetic variants associated with methotrexate efficacy and toxicity in early rheumatoid arthritis: results from the treatment of early aggressive rheumatoid arthritis trial. Pharmacogenomics J 14: 48-53.

Berkani LM, Rahal F, Allam I, et al. (2017) Association of MTHFR C677T and A1298C gene polymorphisms with methotrexate efficiency and toxicity in Algerian rheumatoid arthritis patients. Heliyon 3:e00467.

Churov AV, Oleinik EK, Knip M (2015) MicroRNAs in rheumatoid arthritis: altered expression and diagnostic potential. Autoimmun Rev 14:1029-1037.

Dhaon P, Das SK, Srivastava R, et al. (2017) Performances of Clinical Disease Activity Index (CDAI) and Simplified Disease Activity Index (SDAI) appear to be better than the gold standard Disease Assessment Score (DAS-28-CRP) to assess rheumatoid arthritis patients. Int J Rheum Dis 21:1933-1939.

Galbiatti ALS, Castro R, Caldas HC, et al. (2013) Alterations in the expression pattern of MTHFR, DHFR, TYMS, and SLC19A1 genes after treatment of laryngeal cancer cells with high and low doses of methotrexate. Tumor Biol 34:37653771.

Gómez-Gómez Y, Organista-Nava J, Saavedra-Herrera MV, et al. (2012) Survival and risk of relapse of acute lymphoblastic leukemia in a Mexican population is affected by dihydrofolate reductase gene polymorphisms. Exp Ther 3:665-672.

Goto Y, Yue L, Yokoi A, et al. (2001) A novel singlenucleotide polymorphism in the 3'-untranslated region of the human dihydrofolate reductase gene with enhanced expression. Clin Cancer Res 7:1952-1956.

Gutierrez-Camino A, Umerez M, Santos B, et al. (2018) Pharmacoepigenetics in childhood acute lymphoblastic leukemia: involvement of miRNA polymorphisms in hepatotoxicity. Epigenomics 10:409-417.

Jekic B, Vejnovic D, Milic V, et al. (2016) Association of 63/91 length polymorphism in the DHFR gene major promoter with toxicity of methotrexate in patients with rheumatoid arthritis. Pharmacogenomics 17:1687-1691.

Li K, Tie H, Hu N, et al. (2014) Association of two polymorphisms rs2910164 in miRNA-146a and rs3746444 in miRNA499 with rheumatoid arthritis: a meta-analysis. Hum Immunol 75:602-608.

Miller SA, Dykes DD, Polesky HF (1988) A simple salting out procedure for extracting DNA from human nucleated cells. Nucleic Acids Res 16:1215.

Mishra PJ, Humeniuk R, Mishra PJ, et al. (2007) A miR-24 microRNA binding-site polymorphism in dihydrofolate reductase gene leads to methotrexate resistance. Proc Natl Acad U S A 104:13513-13518.

Murata K, Furu M, Yoshitomi H, et al. (2013) Comprehensive microRNA analysis identifies miR-24 and miR-125a-5p as plasma biomarkers for rheumatoid arthritis. PLoS One 8: e69118.

Naithani M, Saxena V, Mirza AA, et al. (2016) Assessment of folic acid supplementation in pregnant women by estimation of serum levels of tetrahydrofolic acid, dihydrofolate reductase, and homocysteine. Scientifica (Cairo) 2016:1520685.

O'Dell JR, Mikuls TR, Taylor TH, et al. (2013) Therapies for active rheumatoid arthritis after methotrexate failure. N Engl J Med 369:307-318.

Passetti F, Ferreira CG, Costa FF (2009) The impact of microRNAs and alternative splicing in pharmacogenomics. Pharmacogenomics J 9:1-13.

Roy L, Bikorimana E, Lapid D, et al. (2015) MiR-24 is required for hematopoietic differentiation of mouse embryonic stem cells. PLoS Genet 11:e1004959.

Song CQ, Zhang JH, Shi JC, et al. (2014) Bioinformatic prediction of SNPs within miRNA binding sites of inflammatory genes associated with gastric cancer. Asian Pac J Cancer Prev 15:937-943.

Sramek M, Neradil J, Veselska R (2017) Much more than you expected: the non-DHFR-mediated effects of methotrexate. Biochim Biophys Acta 1861:499-503.

Address correspondence to: Mario Salazar-Páramo, MD, PhD, FACR División de Investigación en Salud UMAE Hospital de Especialidades Centro Médico Nacional de Occidente Instituto Mexicano del Seguro Social Guadalajara 44349 México

E-mail:msalazpa@gmail.com 